\title{
Chantal Mouffe. 2018. For a left populism. Londres: Verso.
}

\author{
José Fernández Vega ${ }^{1}$
} ualquiera sea la actitud que se adopte hacia corrientes como el liberalismo o el socialismo, nadie les negaría fundamento filosófico. ¿Sucede lo mismo con el populismo? Demasiado subestimado por casi todo el resto del espectro político, el populismo contemporáneo sólo parece merecer repudios, gritos de alarma o caracterizaciones despectivas. Sería un mero reflejo de los perdedores de la globalización, aferrados a visiones atávicas y animados por resentimientos dirigidos tanto contra la dirigencia democrática como asimismo, en su variante derechista, contra otros perdedores (desocupados, pobres, inmigrantes). El populismo carecería de principios y eso explica que pueda tener expresiones extremas tanto a derecha como a izquierda. Sentimental y amargo, oportunista y altisonante, el populismo no parece ofrecer -quizá tampoco necesitar-ningún respaldo en la teoría. De su lado, las vaporosas definiciones de populismo que circulan en la ciencia política derivaron en un concepto tan abarcador que casi cualquier fenómeno real puede cuadrarle y todo depende de la buena o mala voluntad de quien opere con la noción.

La interpretación elemental del populismo, ampliamente compartida por quienes lo denuncian como el principal peligro que enfrentan las democracias en la actualidad, es implícitamente rechazada por Chantal Mouffe. Su libro no sólo pretende sofisticar la base intelectual sobre la que se asienta una perspectiva populista, sino también asociarla duraderamente a una democracia de izquierda o "radical". La posición que defiende rechaza la xenofobia y el nacionalismo del populismo de la derecha. Aspira a reunir las voluntades de quienes se alzan contra el neoliberalismo en las calles levantando demandas democráticas y sociales. La coyuntura de nuestros días señala un "momento populista" como lo denomina la autora. Con su ensayo pretende intervenir para consolidar una alternativa ante la oportunidad que brinda ese "momento" histórico.

1- Nacionalidad: Argentina. Grado: Doctorado. Especialización: Filosofía. Adscripción: Consejo Nacional de Investigaciones Científicas y Técnicas. Correo electrónico: joselofer@gmail.com. ORCID: http://orcid.org/0000-0002-6857-4786 
Para Mouffe la formación hegemónica neoliberal, pacientemente establecida desde comienzos de los años 1970 hasta proyectarse en una dimensión planetaria, se encuentra en crisis. La situación abre la perspectiva para una ofensiva contra ella que permita un reemplazo democrático y radical. Se pueden albergar dudas acerca de la fragilidad de la hegemonía dominante así como la fuerza de la oposición a ella, descontadas por la autora. ¿No sobrestima ambas dimensiones?

Motorizado por la crisis desencadenada en 2008, el populismo es el primer desafío serio que enfrenta la hegemonía establecida por el mundo de las finanzas y sus oligarquías partidarias llevando la situación a lo que Antonio Gramsci denominó un “interregno" político, argumenta Mouffe. Lo que impera es una posdemocracia porque los dos fundamentos democráticos -la igualdad y la soberanía popular- han sido erosionados por los intereses corporativos y las elites del poder que deciden a espaldas del electorado como en épocas predemocráticas. El espacio político ha sido vaciado de sentido; quedaría mejor retratado como pospolítico. En el no se admiten opciones reales ni otros proyectos de sociedad que compitan por implantarse con éxito. Los ciudadanos se ven impulsados a elegir el mismo programa representado por el "centro político", ese consenso de los partidos tradicionales al servicio de las finanzas que se alternan en gobiernos donde gravitan los expertos y el pueblo no tiene participación alguna. Las consecuencias sociales son bien conocidas. Cada vez más sectores de la sociedad se pauperizan, quedan marginados o viven de trabajos precarizados mientras el poder celebra el individualismo y el consumo. Se vuelve preciso, declara Mouffe, vincular la protesta y la movilización con una política partidaria renovada como la ofrecida en España por Podemos o, del otro lado de los Pirineos, por La France Insoumise.

Las oportunidades para instaurar un paradigma populista de izquierda se amplían a partir de la crisis tanto del marxismo político como de la socialdemocracia. Esta se ha dejado avasallar por el pensamiento neoliberal y se ha convertido en uno de sus factores de multiplicación. Compite ahora por el "centro político" con la derecha y margina a sus votantes históricos que la abandonan luego de haber respaldado su hegemonía durante los años de posguerra. Mouffe reconoce haber abrigado esperanzas de una regeneración de la socialdemocracia europea, pero ya le resultan insostenibles ante la transformación de esa corriente en un socialiberalismo. Además, la crisis ambiental vuelve imposible reflotar el paradigma keynesiano basado en el consumo ampliado. Las preocupaciones ecológicas se volvieron centrales para cualquier proyecto de izquierda.

El marxismo, por su parte, sigue atado a una perspectiva esencialista de clase mientras el voto obrero que lo acompañaba en el pasado migra ahora hacia opciones populistas de derecha como el Front Nationale francés o la Lega italiana, cuyas consignas también contienen elementos democráticos, y a las que no hay que calificar de neofacismos. Tal estigmatización termina siendo la gran excusa de los centristas neoliberales para eludir sus propias responsabilidades en el surgimiento de esas corrientes y descargarlas sobre votantes menospreciados como ignorantes o resentidos. En un plano más especulativo, las promesas marxistas de futuro son irreales. La sociedad siempre mantendrá un resto de opacidad y las disputas dentro de ella son insuprimibles, vis-à-vis la sociedad comunista transparente y armónica. Contra la utopía liberal, animada por una similar metafísica del equilibrio final, Mouffe advierte que libertad e igualdad, liberalismo y democracia, son términos en tensión que jamás alcanzarán una reconciliación total. En estas reflexiones resuena la libre adaptación de unas ideas de Carl Schmitt.

Cuando en 1985 la autora publicó con Ernesto Laclau Hegemonía y estrategia socialista, la política de clase aún parecía poderosa y tenía dificultades para integrar demandas democráticas como, por ejemplo, 
las de las minorías sexuales. Pero dicha política, junto con la legitimidad del keynesianismo de posguerra, sufrió un golpe mortal a partir de la derrota de los mineros a manos de Margaret Thatcher hacia la misma época en que su libro aparecía. Hoy la situación parece haberse invertido o, dicho de otro modo, se extendió hasta abarcar por igual todos los sectores oprimidos sin que pueda distinguirse entre ellos un "agente privilegiado" como lo era la clase obrera. La salida, en tanto, sigue siendo la misma que la señalada por aquel libro. Hay que establecer "cadenas de equivalencia" que articulen las diferentes demandas con el fin de configurar una voluntad común dirigida a la creación de una "hegemonía expansiva”, como la denominó Gramsci. Pero esta rebelión no apunta a un quiebre revolucionario sino a la radicalización de la democracia liberal para que ella llegue a convertirse en lo que siempre prometió ser: un ámbito de emancipación y justicia. La crítica del populismo a la democracia realmente existente es, por lo tanto, inmanente y no pretende suprimir las instituciones existentes, aclara Mouffe. Asistimos al agotamiento de la posdemocracia y no al de la democracia representativa en sí misma, pese a su palmaria descomposición actual.

Un primer paso esencial para la creación de una nueva hegemonía consiste en trazar la línea separadora entre "ellos" -los representantes de la oligarquía- y "nosotros", el pueblo que se reconoce voluntariamente como tal y se construye a través del discurso. Configurado performativamente de cara a un adversario contra el cual se identifica, el pueblo conserva su diversidad interior. Esto significa que "pueblo" no se deja definir por ninguna ontología nacionalista, como sostiene el populismo de derecha para el cual constituye una referencia empírica, unidad homogénea y dada de antemano. Lo que se propone el populismo de izquierda es, en contraste, luchar por la igualdad para todos, recuperar y ampliar la democracia. En un pasaje, Mouffe llega a afirmar que el futuro estará determinado por el combate entre estos dos populismos, el xenofóbico contra el de la justicia social. Focalizado en cerrar filas contra la que, según la autora, es una declinante hegemonía neoliberal que condujo al actual vaciamiento posdemocrático de las sociedades occidentales, poco se dice en su libro sobre ese futuro enfrentamiento entre populismos opuestos. ¿Sobrevendrá dicha batalla una vez que el neoliberalismo expire; o bien, como podemos imaginar, se librará contemporáneamente a la pugna central entre este y los populismos?

Laclau había definido al populismo en términos formales. Se trataba de una política que dividía el escenario en dos campos opuestos mediante estrategias discursivas. No era, por tanto, ni un programa definido ni una ideología ni un régimen político, sino más bien una intervención que, dependiendo del momento y el lugar, podía adquirir las más variadas tonalidades. Desde este nivel teórico, todavía indeterminado, Mouffe pretende elaborar una orientación precisa para configurar un "pueblo" que retome, renovados, los temas que la izquierda convencional es incapaz de seguir impulsando. La distinción izquierda-derecha, desdeñada por el pensamiento único del centro pospolítico, debe ser reivindicada, asegura Mouffe. Aunque pueda limitar las ambiciones populistas de interpelación social transversal, la asociación de "populismo" la palabra "izquierda" resulta preferible a otras expresiones como "progresista" cuyos contornos son demasiado volátiles. Del mismo modo, la noción de adversario necesita ser rehabilitada contra dos contendientes teóricos: la idea de enemigo al que se debe destruir y la de un modelo democrático donde no se admiten voces que alteren el consenso generalizado, como sucede en las democracias contemporáneas.

Otro aspecto de esta nueva visión de lo social es el reconocimiento de los motivos afectivos que se conjugan en las subjetividades políticas, un hecho crucial siempre menospreciado tanto por el marxismo 
como por el liberalismo. Además, la articulación de la cadena de equivalencias destinada a forjar una voluntad común puede ser facilitada por un líder que concentre en su figura carismática la estima popular y contribuya a la consolidación de una política. Este es otro rasgo antiesencialista del populismo, explica Mouffe, porque basa su existencia en identificaciones y afectos inestables dentro de una estructura discursiva en lugar de hacerlo en identidades fijas, en determinaciones materiales o en racionalizaciones del sujeto político.

Mientras los antiguos reformistas son ahora una parte importante del juego de alternancias electorales, los viejos revolucionarios se vuelven cada vez más testimoniales y retóricos. Mouffe desafía la tradicional oposición entre reforma y revolución que signó una parte importante del siglo pasado. Busca establecer una dialéctica entre ellas, porque ambas necesitan ser revividas. Se inclina así por una radicalización del reformismo que no apunte a destruir el Estado, sino que vea en él un campo de batalla por la hegemonía. La propia autora reconoce que esta concepción retoma concepciones de la socialdemocracia antes de que mutara en socialiberalismo. Es aquí donde evoca el nombre de Norberto Bobbio y su valoración de los principios políticos liberales para una política de izquierda.

El pluralismo se ubica en el corazón de una izquierda renovada y pujante, dirigida contra una posdemocracia decadente cuya base es el no reconocimiento de alternativas y el rechazo a admitir la naturaleza hegemónica del orden social con su negatividad implícita y sus antagonismos internos. Esta interpretación dominante no simplemente pone en crisis a la política, sino que desintegra a los partidos que debieran dar forma a la dinámica del conflicto social. Mouffe recupera de Maquiavelo la noción de participación plebeya en la vida cívica republicana pues la acción colectiva resulta esencial para el progreso de la izquierda populista. Lejos de "tomar" el poder del Estado, se trataría de "devenir Estado". Por otra parte, para una democracia el capitalismo resulta contingente; su compañía es algo no esencial, y toda propuesta radical contiene reclamos anticapitalistas. Es claro que para el neoliberalismo la democracia ocupa un lugar secundario, instrumental, frente a la libertad de mercado e individual. Thatcher no hablaba de ciudadanos sino de contribuyentes y consumidores.

En conclusión, según se explica en For a Populist Left, la mayoría popular que quiere asumir el poder no dispone de un plan de gobierno detallado ni ofrece una concreta imagen de la sociedad futura. "Su dinámica, aclara Mouffe, no puede ser determinada de manera aislada de todo contexto de referencia”. El objetivo de esta versión de la izquierda no es ningún "régimen" populista, cuyos contornos nadie conoce, sino la democracia real. 